\title{
Licófitas (Lycopodiophyta) do Corredor de Biodiversidade do Norte do Pará, Brasil
}

\author{
Lycophytes (Lycopodiophyta) of the Northern Pará Biodiversity Corridor, Brazil
}

Luiz Armando de Araújo Góes-Neto ${ }^{1,5}$, Sebastião Maciel², Marcio Roberto Pietrobom ${ }^{3}$, Iván Alberto Valdespino ${ }^{4}$

\begin{abstract}
Resumo
É apresentado o tratamento das licófitas do Corredor de Biodiversidade do Norte do Pará, pertencente ao Centro de Endemismo Guiana. O artigo é parte do projeto "Diagnóstico da Biodiversidade das Unidades de Conservação estaduais do Mosaico Calha Norte, Estado do Pará". Este tratamento inclui chaves de identificação, assim como descrições para as espécies. Na área de estudo foram registradas 14 espécies distribuídas em quatro gêneros (Palhinhaea, Phlegmariurus, Pseudolycopodiella e Selaginella). O gênero mais representativo foi Selaginella com 10 espécies, das quais $S$. fragilis A. Braun e $S$. revoluta Baker são novos registros para o Estado do Pará e S. gynostachya Valdespino e $S$. sandwithii Alston são novos registros para a flora brasileira. Palavras-chave: Amazônia, Centro de Endemismo Guiana, Lycopodiaceae, Selaginella.
\end{abstract}

\begin{abstract}
A treatment of the lycophytes of the Northern Pará Biodiversity Corridor within the Guiana Endemism Center is presented. This article is part of the project "Diagnóstico da Biodiversidade das Unidades de Conservação estaduais do Mosaico Calha Norte, Estado do Pará". The treatment includes keys as well as species descriptions. In the study area 14 species distributed in four genera (Palhinhaea, Phlegmariurus, Pseudolycopodiella and Selaginella) were registered. The most diverse genus was Selaginella with 10 species, of which $S$. fragilis A. Braun and S. revoluta Baker are new records for Pará, and S. gynostachya Valdespino and S. sandwithii Alston are reported here as new to the Brazilian flora.
\end{abstract}

Key words: Amazonia, Guiana Endemism Center, Lycopodiaceae, Selaginella.

\section{Introdução}

As licófitas compõem um grupo monofilético (Banks 2009) com cerca de 1.500 espécies distribuídas nas famílias Isoetaceae, Lycopodiaceae e Selaginellaceae (Jermy 1990; Hickey et al. 2003; Øllgaard \& Windisch 2014). Possui como principais características as folhas do tipo microfilo e os esporângios com deiscência transversal presentes na axila adaxial do esporofilo, geralmente formando estróbilos no ápice dos ramos (Tryon \& Tryon 1982).

O estudo da pteridoflora do Brasil iniciouse tardiamente (Øllgaard \& Windisch 2014). Dentre as diversas publicações abordando as espécies brasileiras de licófitas, destacam-se os trabalhos pioneiros de Spring (1840) e Fée (1869, 1872-1873). Posteriormente, nos séculos XX e XXI, foram publicados alguns trabalhos abordando exclusivamente os representantes das licófitas, dentre estes, os estudos florísticos de Nessel (1927, 1955), Alston (1936), Fuchs-Eckert (1986), Øllgaard \& Windisch (1987), Castellani \& Freitas (1992), Edwards (1995), Barros \& Fonseca (1996), Hirai \& Prado (2000), Freitas \& Windisch (2005), Prado \& Freitas (2005), Hirai (2007), Prado \& Hirai (2008), Assis \& Labiak (2009) e Ramos \& Sylvestre (2010). No que diz respeito a descrições de espécies novas, têm-se os estudos

\footnotetext{
${ }^{1}$ Universidade Federal de Minas Gerais, Inst. Ciências Biológicas, Av. Antônio Carlos 6627, 31270-901, Pampulha, Belo Horizonte, MG, Brasil.

${ }^{2}$ Museu Paraense Emílio Goeldi, Campus de Pesquisa, Coordenação de Botânica, Av. Perimetral 1901, 66077-830. Terra Firme, Belém, PA, Brasil

${ }^{3}$ Universidade Federal do Pará, Campus de Bragança, Inst. Estudos Costeiros, Alameda Leandro Ribeiro s/n, 68000-000, Aldeia, Bragança, PA, Brasil.

${ }^{4}$ Universidad de Panamá, Estafeta Universitaria, Apartado 3366, El Cangrejo, Ciudad de Panamá, Panamá.

${ }^{5}$ Autor para correspondência: lgoes-neto@hotmail.com
} 
de Silveira (1898), Bautista (1974a; b), Windisch (1991), Hickey et al. (2009) e Pereira et al. (2012). Já para as revisões taxonômicas, destacam-se os recentes trabalhos de Øllgaard (2012) e Øllgaard \& Windisch (2014).

No Pará, o estudo das plantas vasculares sem sementes obteve um grande avanço a partir do ano de 2003 (Góes-Neto \& Pietrobom 2012b). Dentre os diversos artigos florístico-taxonômicos abordando as espécies paraenses, o único que trata exclusivamente das licófitas é o de Pietrobom et al. (2009), onde os autores registraram quatro espécies na Floresta Nacional de Caxiuanã, sendo duas espécies pertencentes à família Lycopodiaceae e duas pertencentes à família Selaginellaceae.

O Corredor de Biodiversidade do Norte do Pará (CBNP) possui algumas das mais importantes Unidades de Conservação amazônicas (Pará 2008). O CBNP está inserido no Centro de Endemismo Guiana, conhecido como o maior dentre os oito centros de endemismo da região amazônica, possuindo metade de sua superfície em território brasileiro (Avila-Pires et al. 2010). A região guianense compartilha diversas espécies com outras áreas da Amazônia, mas também possui um alto índice de endemismo, isto principalmente pela sua distinta geografia (Avila-Pires et al. 2010).

Este estudo é parte do projeto "Diagnóstico da Biodiversidade das Unidades de Conservação Estaduais do Mosaico Calha Norte, Estado do Pará" e objetivou inventariar as espécies de licófitas e samambaias em cinco Unidades de Conservação no Corredor de Biodiversidade do Norte do Pará. Neste artigo são apresentadas as espécies pertencentes à linhagem das licófitas, aumentando o conhecimento sobre tais vegetais na Amazônia Brasileira e fornecendo informações que subsidiarão outros estudos e ações conservacionistas.

\section{Material e Métodos}

As informações sobre a localização e caracterização geral do CBNP (Fig. 1), estão disponíveis em Huber (2006), Rossetti \& Toledo (2007), Funk et al. (2007), Avila-Pires et al. (2010) e Aleixo et al. (2011).

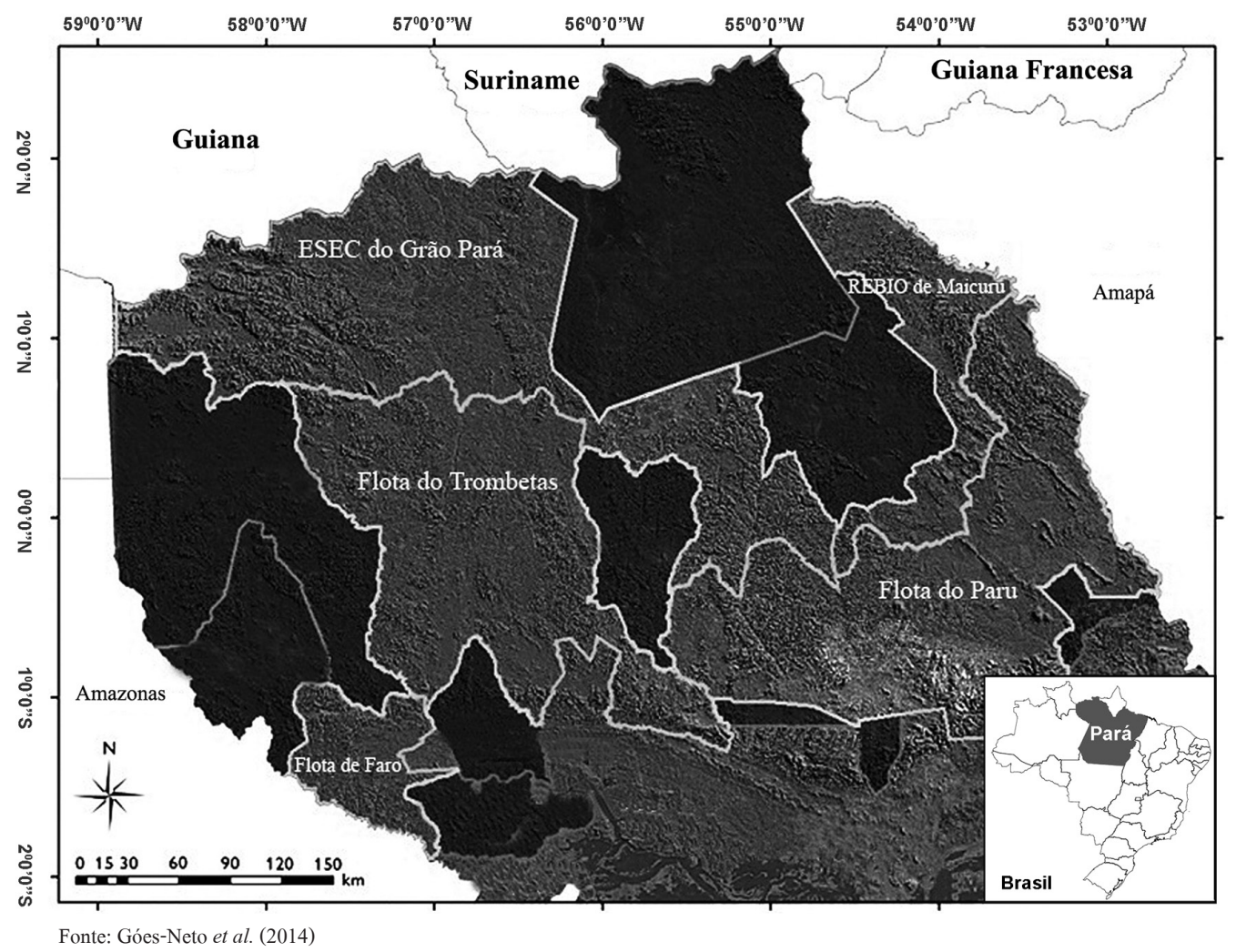

Figura 1 - Corredor de Biodiversidade do Norte do Pará e as cinco Unidades de Conservação inventariadas. Figure 1 - North Pará Biodiversity Corridor and the five Conservation Units inventoried. 
Os locais onde se realizaram as coletas, bem como a metodologia utilizada na coleta e herborização dos espécimes estão descritas em Góes-Neto \& Pietrobom (2012a,b). O material coletado encontra-se depositado no herbário MG com duplicadas doadas para os herbários ICN e PMA. Além do material coletado, foram analisadas exsicatas dos herbários MG e IAN. Os acrônimos dos herbários seguem Thiers (continuously updated).

As descrições e as chaves de identificação foram elaboradas apenas com base no material analisado. As terminologias utilizadas nas descrições estão de acordo com Lellinger (2002).

A família Selaginellaceae está classificada de acordo com Jermy (1990) e a família Lycopodiaceae está classificada de acordo com Øllgaard (2012). As abreviações dos nomes dos autores dos táxons seguem Pichi Sermolli (1996).

A distribuição geográfica dos táxons no país está baseada na Lista de Espécies da Flora do Brasil (Windisch et al. (2014) para Lycopodiaceae e Hirai (2014) para Selaginellaceae), por vezes complementada por outra bibliografia indicada no texto.

Devido à distinta morfologia de Selaginella, o uso dos termos "adaxial" e "abaxial" pode causar uma má interpretação. Neste gênero, a face superior dos microfilos laterais e axilares corresponde à face adaxial, porém, nos microfilos dorsais, a face superior corresponde à face abaxial (Valdespino 1995). Desta forma, seguiu-se Mital (1969) e Valdespino (1995) onde a face superior representa a superfície oposta ao solo, onde estão inseridos os microfilos dorsais e a face inferior representa a superfície voltada para o solo, onde estão inseridos os microfilos laterais e axilares.

São apresentadas ilustrações apenas das espécies de Selaginella, uma vez que estas estão menos representadas na literatura e carecem desta informação.

\section{Resultados e Discussão}

Foram registradas no CBNP 14 espécies pertencentes a quatro gêneros (Pseudolycopodiella Holub, Palhinhaea Vasc. \& Franco, Phlegmariurus (Herter) Holub e Selaginella P. Beauv.) e duas famílias (Lycopodiaceae Mirb. e Selaginellaceae Willk.). O gênero mais representativo foi Selaginella com 10 espécies. Dentre estas, duas são novos registros para o Estado do Pará (S. fragilis A. Braun e $S$. revoluta Baker) e duas são novos registros para o Brasil (S. gynostachya Valdespino e $S$. sandwithii Alston).

\section{Chave de identificação para as famílias de licófitas do CBNP}

1. Plantas homosporadas; esporângios ao longo da porção distal do ramo, não formando estróbilos ou esporângios formando estróbilos cilíndricos na extremidade dos ramos; microfilos estéreis dispostos em espiral Lycopodiaceae

1'. Plantas heterosporadas; esporângios sempre em estróbilos achatados ou quadrangulares na extremidade dos ramos; microfilos estéreis dispostos em fileiras Selaginellaceae

Lycopodiaceae Mirb. in Lam. \& Mirb., Hist. Nat. Veg. 4: 293. 1802.

Família formada por 16 gêneros cosmopolitas (Øllgaard 2012) com aproximadamente 400 espécies, cerca de metade destas neotropicais
(Øllgaard \& Windisch 2014). No Brasil são conhecidos nove gêneros e 61 espécies (Windisch et al. 2014). Na área estudada foram registradas quatro espécies distribuídas em três gêneros.

\section{Chave de identificação para as espécies de Lycopodiaceae do CBNP}

1. Porção aérea do caule dicotomicamente ramificada, sem um eixo principal definido; esporofilos semelhantes aos microfilos estéreis, não agrupados em estróbilos

1'. Porção aérea do caule não ramificada ou lateralmente ramificada, com um eixo principal definido; esporofilos diferentes dos microfilos estéreis, agrupados em estróbilos terminais. 
2. Caule longo-reptante, com aparência achatada; ramo aéreo não ramificado; microfilos estéreis anisófilos; estróbilos eretos, pedunculados e solitários..... 4. Pseudolycopodiella meridionalis

2'. Caule ereto, com aparência cilíndrica; ramo aéreo ramificado; microfilos estéreis isófilos; estróbilos pendentes, sésseis e numerosos.

3. Ramos laterais ascendentes; ramos de $2^{\mathrm{a}}$ ordem suberetos, rígidos e ascendentes; microfilos densamente agregados; tricomas presentes em cada bifurcação dos ramos laterais

1. Palhinhaea camporum

3'. Ramos laterais patentes; ramos de $2^{\mathrm{a}}$ ordem arqueados, flexíveis e pendentes; microfilos espaçados; tricomas ausentes nas bifurcações dos ramos laterais. 2. Palhinhaea cernua

1. Palhinhaea camporum (B. Øllg. \& P.G. Windisch) Holub, Folia Geobot. Phytotax. 26: 93. 1991.

Caule ereto, com aparência cilíndrica. Microfilos estéreis isófilos, lineares, esverdeados, arqueados em direção ao ápice, densamente agregados, dispostos em espiral. Ramos laterais ascendentes, dicotomicamente ramificados, com tricomas curtos e eretos em suas bifurcações, ramos de $2^{\mathrm{a}}$ ordem suberetos, rígidos e ascendentes. Esporofilos ovados com as margens erodidas. Esporângios sésseis, axilares, agrupados em numerosos estróbilos pendentes, sésseis e terminais.

Distribui-se na Colômbia, Venezuela, Guiana, Suriname, Guiana Francesa, Peru, Bolívia (Øllgaard 1995a) e Brasil, onde está registrada em todos os estados da Região Norte, na Bahia, Pernambuco, Piauí, em todo o Centro-Oeste, em Minas Gerais, São Paulo, Paraná e Santa Catarina. $P$. camporum assemelha-se à $P$. cernua (L.) Vasc. \& Franco na maioria dos detalhes, porém esta última possui os ramos estéreis flexíveis, patentes e arqueados com os microfilos espaçados, enquanto que $P$. camporum possui os ramos estéreis mais densamente folhosos, rigidamente ascendentes e não recurvados. A espécie ocorre preferencialmente em ambientes abertos, em solo arenoso periodicamente alagado. Espécime coletado em campo pedregoso.

Material examinado: BRASIL. PARÁ: Trombetas, Taboleta, Campo do Ariramba, 30.V.1957, P. Cavalcante 147 (MG).

2. Palhinhaea cernua (L.) Vasc. \& Franco, Bol. Soc. Brot., sér. 2, 41: 25. 1967.

Caule ereto, com aparência cilíndrica. Microfilos estéreis isófilos, lineares, esverdeados, arqueados em direção ao ápice, espaçados, dispostos em espiral. Ramos laterais patentes, pinadamente ramificados, sem tricomas em suas bifurcações, ramos de $2^{\mathrm{a}}$ ordem arqueados, flexíveis e pendentes. Esporofilos sub-deltóides com as margens ciliadas. Esporângios sésseis, axilares, agrupados em numerosos estróbilos pendentes, sésseis e terminais.

A espécie distribui-se nos Paleotrópicos, EUA, do México ao Paraguai (Øllgaard 1995b; Mickel \& Smith 2004) e no Brasil, onde possui registros em todos os estados, com exceção do Piauí, Rio Grande do Norte e Sergipe. Comumente observada como pioneira em ambiente antropizado. Espécime coletado como terrícola em borda de mata, próximo a um curso d'água. Floresta de terra firme, ca. $76 \mathrm{~m}$ de altitude.

Material examinado: BRASIL. PARÁ: Almeirim, Distrito de Monte Dourado, área de manejo da Orsa Florestal, $01^{\circ} 09^{\prime} 48^{\prime \prime}$ S-52 $37^{\prime} 35^{\prime \prime} \mathrm{W}, 31 . V .2010$, E.S. Leal \& R.C. Forzza $172(\mathrm{MG})$.

3. Phlegmariurus dichotomus (Jacq.) W.H. Wagner, Novon 3(3): 305. 1993.

Caule ereto, com aparência cilíndrica. Microfilos estéreis isófilos, lanceolados, paleáceos a esverdeados. Ramos aéreos dicotomicamente ramificados, sem um eixo principal distinto. Esporofilos semelhantes aos microfilos estéreis. Esporângios sésseis, axilares, não formando estróbilos.

Distribui-se dos EUA ao Paraguai (Øllgaard 1995a; Mickel \& Smith 2004) e Brasil, onde possui registros nos estados do Acre, Amapá, Pará, Rondônia, Roraima, Ceará, Mato Grosso, Rio de Janeiro e Paraná (Nessel 1955; Øllgaard \& Windisch 1987; Edwards 1998). Alguns exemplares apresentaram grande variação no seu grau de compactação, assim como constatado por Øllgaard (1992). Coletada como epífita sobre tronco em decomposição, em área aberta, próximo a um igapó. Floresta ombrófila aberta, ca. $230 \mathrm{~m}$ de altitude.

Material examinado: BRASIL. PARÁ: Almeirim, Reserva Biológica do Maicuru, $00^{\circ} 48^{\prime} 44,8^{\prime \prime} \mathrm{S}-$ 5356'55,7'W, 26.X.2008, S. Maciel 1416 (MG, ICN). 
4. Pseudolycopodiella meridionalis (Underw. \& F.E. Lloyd) Holub, Folia Geobot. Phytotax. 18: 442. 1983.

Caule longo-reptante, com aparência achatada. Microfilos estéreis anisófilos, microfilos laterais deltado-ovados, levemente falcados, ápice agudo a acuminado, microfilos dorsais lanceolados a deltado-lanceolados, ápice agudo a acuminado. Porção aérea ereta, não ramificada, com um eixo principal definido, microfilos linearlanceolados, dispostos em espiral. Esporofilos ovado-cuspidados a deltado-acuminados, com as margens denticuladas a curtamente fimbriadas. Esporângios sésseis, axilares, agrupados em um único estróbilo ereto, pedunculado e terminal.

Distribui-se na Ásia, África tropical, do México ao Peru (Øllgaard 1995a; Mickel \& Smith 2004) e Brasil, onde possui registros nos estados do Amazonas, Amapá, Roraima, Pará, Bahia, Pernambuco, Distrito Federal, Minas Gerais, Rio de
Janeiro e São Paulo e em todos os estados da Região Sul (Costa \& Pietrobom 2007). P. meridionalis difere das demais espécies registradas na área pelo ramo aéreo ereto, não ramificado, com estróbilo apical solitário e microfilos estéreis anisófilos. Coletada em campo alagado.

Material examinado: BRASIL. PARÁ: Trombetas, Ariramba, Taboleta 30.V.1957, W.A. Egler 419 (MG).

Selaginellaceae Willk., Anleit. Stud. Bot. 2: 163. 1854.

Família monogenérica (Selaginella P. Beauv.) com cerca de 750 espécies (Jermy 1990) distribuídas principalmente nas zonas tropicais do mundo, algumas destas colonizando as zonas árticoalpinas em ambos os hemisférios (Jermy 1990; Mickel et al. 2004). No Brasil são conhecidas 55 espécies (Hirai 2014), destas, três são introduzidas. $\mathrm{Na}$ área estudada foram registradas 10 espécies.

\section{Chave de identificação para as espécies de Selaginella do CBNP}

1. Caule articulado.

2. Microfilos curto-ciliados

2'. Microfilos denticulados.

3. Rizóforos distribuídos por toda a planta; caule comumente com ápice flageliforme ..............

10. Selaginella sulcata

3'. Rizóforos restritos à base do caule; caule sem ápice flageliforme.

3. Selaginella fragilis

4. Microfilo lateral com a aurícula acroscópica menos desenvolvida que a basioscópica; microfilo axilar geralmente sem aurícula ou com duas aurículas curtas e inconspícuas 5. Selaginella parkeri

4'. Microfilo lateral com a aurícula acroscópica do mesmo tamanho ou mais desenvolvida que a basioscópica; microfilo axilar com duas longas aurículas.

1'. Caule não articulado.

1. Selaginella conduplicata

5. Base do microfilo lateral longo-ciliada.

6. Rizóforos restritos à base do caule; base do microfilo axilar arredondada; porção basioscópica do microfilo lateral plana; caule 2-3-pinado. 7. Selaginella radiata

6'. Rizóforos distribuídos por toda a planta; base do microfilo axilar sub-cordiforme; porção basioscópica do microfilo lateral geralmente revoluta; caule 1-2-pinado.....

5'. Base do microfilo lateral denticulada a eventualmente curto-ciliada.

8. Selaginella revoluta

7. Caule comumente com ápice flageliforme, 3-4-pinado.

7'. Caule sem ápice flageliforme, 2-3-pinado.

8. Microfilo dorsal com ápice aristado; microfilo lateral com tricomas curtos na face superior, principalmente próximo às margens 9. Selaginella sandwithii

8'. Microfilo dorsal com ápice agudo a acuminado; microfilo lateral sem tricomas na face superior.

9. Microfilo dorsal ovado-elíptico, com uma pequena aurícula na porção externa; rizóforos restritos à metade basal da planta; caule 2-3-pinado.

4. Selaginella gynostachya

9'. Microfilo dorsal ovado, sem aurícula; rizóforos distribuídos por toda a planta; caule 2-pinado 6. Selaginella producta 
1. Selaginella conduplicata Spring in Mart., Fl. Bras. 1(2): 129, no.19. $1840 . \quad$ Fig. 2a-c

Caule articulado, paleáceo, não flageliforme, 2-3-pinado. Rizóforos restritos à porção basal do caule. Microfilos laterais lanceolados, ápice agudo, base com duas aurículas denticuladas, assimétricas, face superior glabra, margem acroscópica esbranquiçada e denticulada. Microfilos dorsais ovado-lanceolados com ápice acuminado a longamente agudo, base com apenas uma aurícula no lado externo, margens denticuladas. Microfilos axilares lanceolados, ápice agudo, base com duas longas aurículas, margens denticuladas, dentículos maiores e mais abundantes sobre as aurículas. Estróbilo quadrangular. Esporofilos monomorfos. Esporofilo dorsal verde, ascendente; esporofilo ventral verde, ascendente.

Distribui-se na Guiana, Suriname, Guiana Francesa, Colômbia, Peru e no Brasil (Smith 1995), onde é conhecida nos estados do Amazonas e Pará. $S$. conduplicata distingue-se das demais espécies da área pelo microfilo axilar com duas aurículas conspícuas e microfilo lateral com duas aurículas assimétricas (raramente semelhantes). Alguns exemplares analisados apresentaram as aurículas do microfilo lateral bastante semelhantes no tamanho e forma, porém, a maioria dos espécimes apresentou a aurícula acroscópica muito mais longa que a basioscópica. Coletada como terrícola às margens da trilha. Floresta de terra firme em área de campinarana alta, ca. $60 \mathrm{~m}$ de altitude.

Material examinado: BRASIL. PARÁ: Faro, Floresta Estadual de Faro, margem esquerda do Rio Nhamundá, $1^{\circ} 41^{\prime} 23^{\prime}$ 'S-57 $15^{\circ}$ '09,5”'W, 26.I.2008, M.R. Pietrobom \& G. Teixeira 7525 (MG, PMA).

2. Selaginella flagellata Spring, Bull. Acad. Roy. Sci. Bruxelles 10: 228, no 119. 1843 . Fig. 2d-f

Caule não articulado, paleáceo a verdeclaro, quase sempre flageliforme, 3-4-pinado. Rizóforos restritos à base do caule. Microfilos laterais oblongos, ápice agudo, base assimétrica com a porção acroscópica sobrepondo o caule, sem aurículas, face superior glabra, margem acroscópica denticulada. Microfilos dorsais ovados, ápice aristado, base assimétrica com a porção externa um pouco maior, porém, sem formar aurícula, margens denticuladas. Microfilos axilares oblongos, ápice agudo, base sem aurículas, margens denticuladas. Estróbilo achatado dorsiventralmente. Esporofilos dimorfos. Esporofilo dorsal verde, patente; esporofilo ventral hialino a verde claro, ascendente.
Distribui-se do México à Bolívia e no Brasil (Mickel et al. 2004), onde possui registros nos estados do Acre, Amazonas, Amapá, Pará, Rondônia, Tocantins, Goiás e Mato Grosso (Valdespino 1995). S. flagellata pode ser reconhecida pelo caule com ápice flageliforme, microfilos delicados, verde claros, microfilos dorsais longo-aristados, estróbilos achatados dorsiventralmente e micrósporos com papilas alongadas (Alston et al. 1981; Mickel et al. 2004). Dentre as espécies da região guianense, $S$. flagellata assemelha-se às espécies $S$. tenella $(\mathrm{P}$. Beauv.) Spring, diferenciando-se por esta última possuir microfilos dorsais amplamente ovados com ápice agudo e base oblíqua a cordada; S. muscosa Spring, diferenciando-se por esta possuir estróbilos tetragonais, hábito prostrado e caule sem ápice flageliforme; S. pearcei Baker, diferenciandose por esta possuir coloração verde escuro com os microfilos dorsais curtamente aristados e $S$. sandwithii Alston, diferenciando-se por esta ser mais ereta, possuir caule sem ápice flageliforme, possuir curtos tricomas na face superior dos esporofilos laterais e micrósporos verrucosos. Coletada como epífita sobre tronco em decomposição. Floresta de terra firme.

Material examinado: BRASIL. PARÁ: margem oeste do Rio Maicuru, $00^{\circ} 55^{\prime}$ 'S-54'26'W, 29.VII.1981, J.J. Strudwick et al. 3696 (MG).

3. Selaginella fragilis A. Braun, Ann. Sci. Nat,, Bot., sér. 5, 3: 305. $1865 . \quad$ Fig. 3a-c Caule articulado, paleáceo, comumente flageliforme, 2-3-(4)-pinado. Rizóforos distribuídos por toda a planta. Microfilos laterais lanceolados, ápice agudo, base com uma aurícula (por vezes inconspícua) na porção basioscópica, face superior glabra, margem acroscópica e aurícula denticuladas. Microfilos dorsais ovados, ápice acuminado, base com apenas uma aurícula no lado externo, margens e aurícula denticulados. Microfilos axilares com ápice agudo, base truncada sem aurículas, margens denticuladas. Estróbilo quadrangular. Esporofilos monomorfos. Esporofilo dorsal verde, ascendente; esporofilo ventral verde, ascendente.

Distribui-se na Colômbia, Venezuela e Brasil, onde era conhecida apenas no estado do Amazonas (Smith 1995) e agora está sendo registrada no Pará. A distinção entre alguns espécimes de $S$. fragilis e $S$. parkeri (Hook \& Grev.) Spring. muitas vezes é difícil, já que estas duas espécies são muito semelhantes e $S$. parkeri apresenta uma ampla variabilidade morfológica. Apesar de reconhecerem 

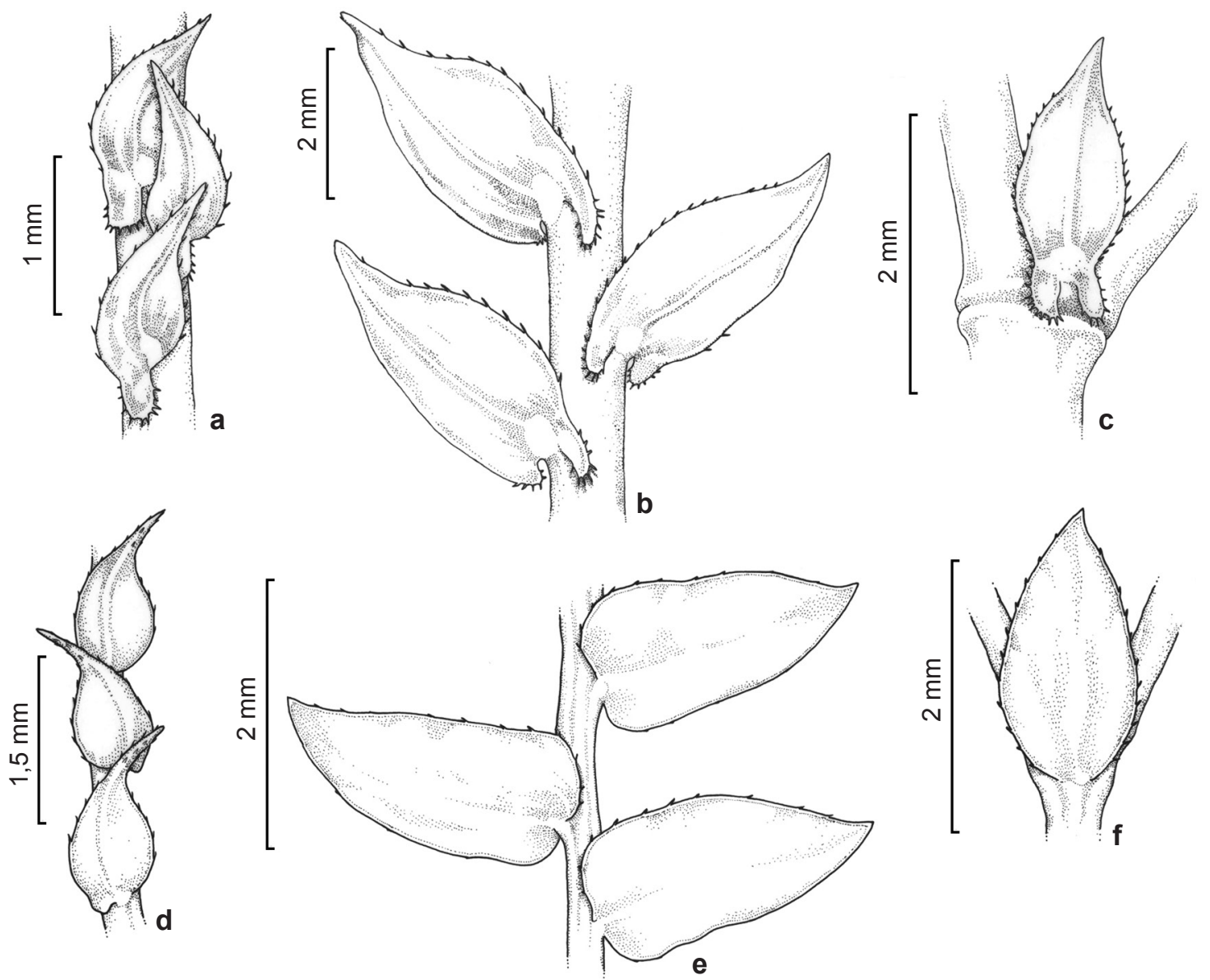

Figura 2 - a-c. Selaginella conduplicata (M.R. Pietrobom \& G. Teixeira 7525). a. microfilos dorsais. b. microfilos laterais. c. microfilo axilar. d-f. Selaginella flagellata (J.J. Strudwick et al. 3696). d. microfilos dorsais. e. microfilos laterais. f. microfilo axilar.

Figure 2 - a-c. Selaginella conduplicata (M.R. Pietrobom \& G. Teixeira 7525). a. median microphylls. b. lateral microphylls. c. axillary microphyll. d-f. Selaginella flagellata (J.J. Strudwick et al. 3696). d. median microphylls. e. lateral microphylls. f. axillary microphyll.

ambas as espécies, Alston et al. (1981) comentam que $S$. fragilis talvez não seja realmente distinta de S. parkeri, pois, segundo eles, estas diferenciam-se apenas por $S$. fragilis possuir ramos com crescimento indeterminado, com rizóforos distribuídos por toda a planta, enquanto que S. parkeri não possui ápice flageliforme e possui os rizóforos restritos à base do caule. Estudos palinológicos em ambas as espécies podem ajudar a elucidar este problema. Coletada como terrícola às margens da trilha, em barranco na encosta e próximo a um igarapé. Floresta ombrófila aberta de terra firme e floresta submontana aberta, entre 60-570 $\mathrm{m}$ de altitude.

Material selecionado: BRASIL. PARÁ: Almeirim, $00^{\circ} 49^{\prime} 51,9^{\prime \prime} \mathrm{N}-53^{\circ} 57^{\prime} 19,6^{\prime}$ 'W, 27.X.2008, S. Maciel 623 (MG, PMA); Oriximiná, $01^{\circ} 16^{\prime} 16,8^{\prime \prime} \mathrm{N}-58^{\circ} 48^{\prime} 0,6^{\prime \prime} \mathrm{W}$,
04.IX.2008, M.R. Pietrobom \& S. Maciel 8043 (MG, PMA); idem, $01^{\circ} 16^{\prime} 00,3^{\prime}{ }^{\prime} \mathrm{N}-58^{\circ} 41^{\prime} 45,5^{\prime}$ 'W, 29.VIII.2008, S. Maciel \& M.R. Pietrobom 834 (MG, PMA); idem, $01^{\circ} 16^{\prime} 00,3^{\prime \prime} \mathrm{N}-58^{\circ} 41^{\prime} 45,5^{\prime} \mathrm{W}, 29 . \mathrm{VIII} .2008$, S. Maciel \& M.R. Pietrobom 926(MG, PMA); Faro, margem esquerda do Rio Nhamundá, $1^{\circ} 42^{\prime} 23,3$ '"S-57 $7^{\circ} 12^{\prime} 10,1$ 'W, 17.I.2008, M.R. Pietrobom \& G. Teixeira 7286 (MG, PMA).

4. Selaginella gynostachya Valdespino, Fern. Gaz. 18(2): 42.2007.

Fig. 3d-f

Caule não articulado, paleáceo, não flageliforme, 2-3-pinado. Rizóforos restritos à metade basal do caule. Microfilos laterais oblongos, ápice obtuso a agudo, base assimétrica com a porção acroscópica sobrepondo o caule, sem aurículas, face superior glabra, margem 
acroscópica curtamente denticulada. Microfilos dorsais ovado-elípticos, ápice agudo a acuminado, base com uma pequena aurícula no lado externo, margens denticuladas. Microfilos axilares ovados a oblongo-ovados, ápice obtuso a agudo, base arredondada, sem aurícula, margens denticuladas. Estróbilo achatado dorsiventralmente. Esporofilos dimorfos. Esporofilo dorsal verde, patente; esporofilo ventral hialino a verde claro, ascendente.

A espécie distribui-se na Venezuela, Guiana e Guiana Francesa (Valdespino 1995), sendo este o primeiro registro no Brasil. S. gynostachya assemelha-se à $S$. karowtipuensis Valdespino (espécie que ocorre na região guianense), diferindo por esta última possuir microfilos dorsais com a base sub-cordada a redonda, idioblastos na face superior dos microfilos laterais e microfilo dorsal longo-acuminado a curto-aristado, enquanto que $S$. gynostachya possui a base dos microfilos dorsais sub-truncada a redonda, não possui idioblastos na face superior dos microfilos laterais, possui microfilos dorsais elípticos a ovado-elípticos ou amplamente ovados, microfilo dorsal com ápice agudo a curto-acuminado e megásporos amareloclaros (Valdespino 1995). Coletada como terrícola no interior da parcela e como rupícola em grota. Floresta ombrófila aberta, ca. $600 \mathrm{~m}$ de altitude.

Material examinado: BRASIL. PARÁ: Oriximiná, 01 ${ }^{\circ} 96^{\prime} 32,1^{\prime \prime} \mathrm{N}-58^{\circ} 41^{\prime} 29,2^{\prime \prime} \mathrm{W}, 27 . \mathrm{VIII} .2008$, S. Maciel \& M.R. Pietrobom 800 (MG, PMA); idem, $01^{\circ} 16^{\prime} 39,6^{\prime \prime} \mathrm{N}-$ 5840'16,1'W, 01.IX.2008, S. Maciel \& M.R. Pietrobom 1032 (MG, PMA).
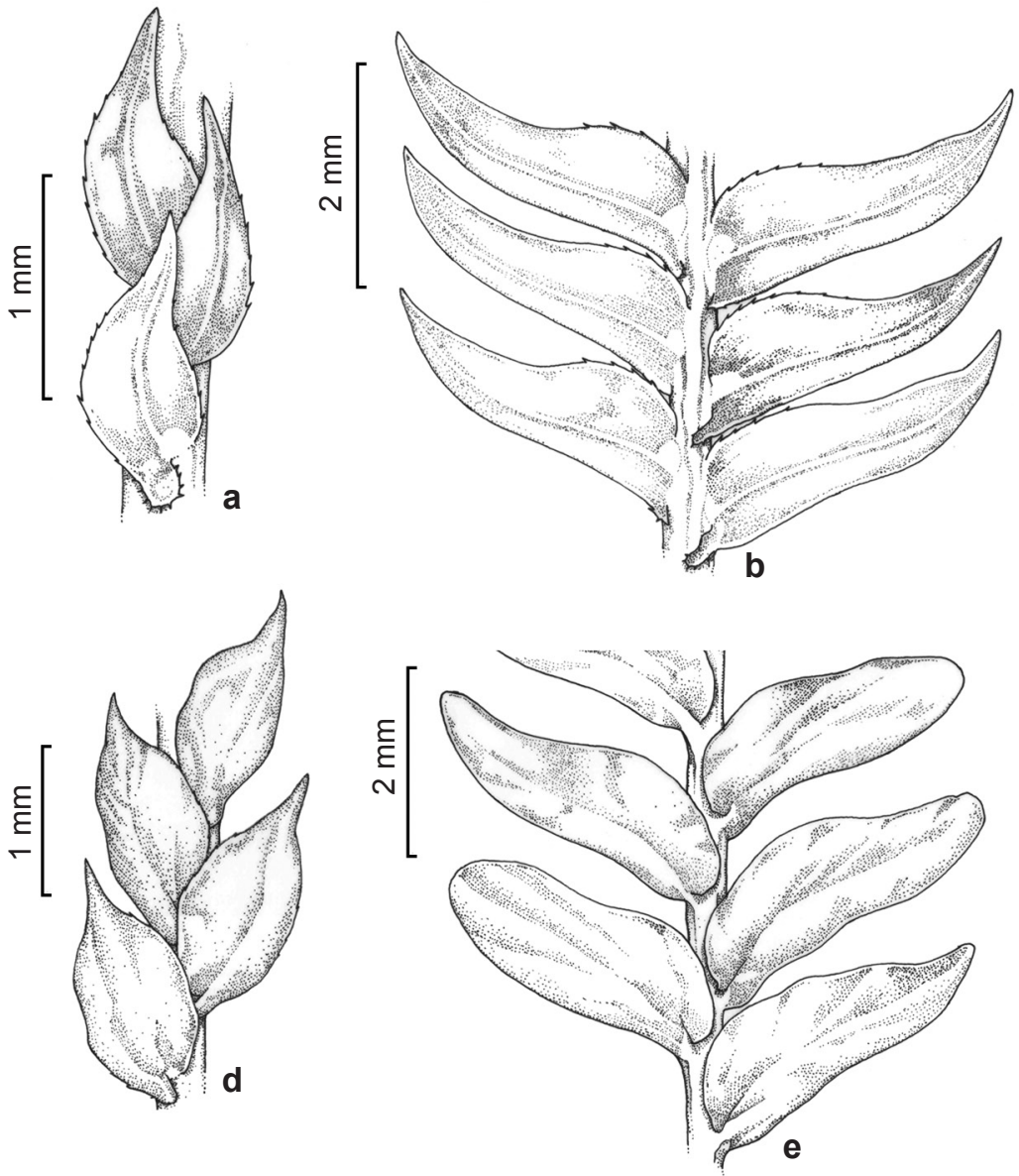
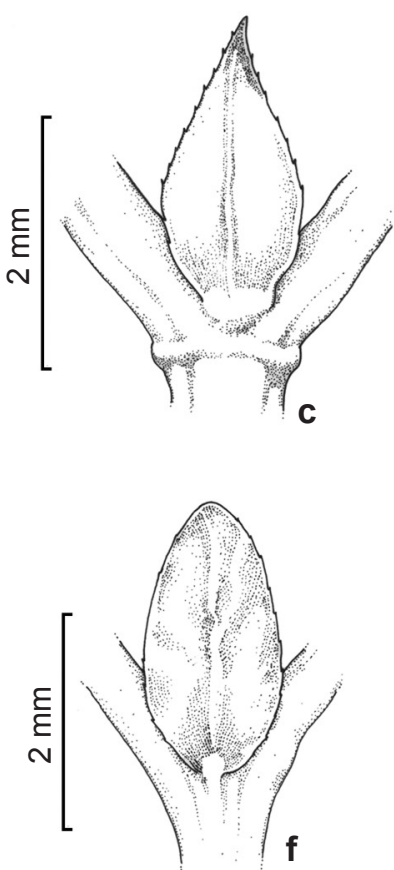

Figura 3 - a-c. Selaginella fragilis (S. Maciel \& M.R. Pietrobom 834). a. microfilos dorsais. b. microfilos laterais. c. microfilo axilar. d-f. Selaginella gynostachya (S. Maciel \& M.R. Pietrobom 800). d. microfilos dorsais. e. microfilos laterais. f. microfilo axilar.

Figure 3 - a-c. Selaginella fragilis (S. Maciel \& M.R. Pietrobom 834). a. median microphylls. b. lateral microphylls. c. axillary microphyll. d-f. Selaginella gynostachya (S. Maciel \& M.R. Pietrobom 800). d. median microphylls. e. lateral microphylls. f. axillary microphyll. 
5. Selaginella parkeri (Hook. \& Grev.) Spring, Bull. Acad. Roy. Sci. Bruxelles 10: 146. 1843.

Fig. 4a-c

Caule articulado, paleáceo, não flageliforme, 3-4-pinado. Rizóforos restritos à base do caule. Microfilos laterais lanceolados, ápice agudo, base com duas aurículas (a acroscópica menor e às vezes inconspícua), face superior glabra, margem acroscópica e aurículas denticuladas. Microfilos dorsais ovado-lanceolados, ápice longamente agudo, base com apenas uma aurícula do lado externo, margens e aurícula denticulados. Microfilos axilares lanceolados, ápice agudo, base geralmente sem aurícula ou com duas curtas aurículas inconspícuas, margens e aurículas denticuladas. Estróbilo quadrangular. Esporofilos monomorfos. Esporofilo dorsal verde, ascendente; esporofilo ventral verde, ascendente.

Distribui-se na Colômbia, Venezuela, Guiana, Suriname, Guiana Francesa e Brasil, (Smith 1995) onde está registrada apenas no bioma amazônico, nos estados do Acre, Amazonas e Pará. Os espécimes examinados de $S$. parkeri apresentaram uma grande variabilidade morfológica quanto à dissecção da lâmina, presença/ausência e tamanho das aurículas no microfilo axilar, bem como na forma e tamanho dos tricomas. De acordo com Alston et al. (1981) a espécie caracteriza-se por possuir 2-3-estróbilos no ápice de cada ramo. Além da característica citada, as curtas aurículas de tamanhos desiguais do microfilo lateral e as curtas aurículas do microfilo axilar distinguem $S$. parkeri das demais espécies ocorrentes na área estudada. Coletada como terrícola no interior da parcela e às margens de um igarapé. Floresta ombrófila aberta, entre 230-600 $\mathrm{m}$ de altitude.

Material selecionado: BRASIL. PARÁ: Oriximiná, 01 ${ }^{\circ} 96^{\prime} 32,1^{\prime \prime} \mathrm{N}-58^{\circ} 41^{\prime} 29,2^{\prime}$ 'W, 27.VIII.2008, S. Maciel \& M.R. Pietrobom 771 (MG, PMA); idem, $01^{\circ} 16^{\prime} 00,3^{\prime}{ }^{\prime} \mathrm{N}-$ $58^{\circ} 41^{\prime} 45,5^{\prime}$ 'W, 29.VIII.2008, S. Maciel \& M.R. Pietrobom 826 (MG, PMA); idem, $01^{\circ} 16^{\prime} 39,6^{\prime} \mathrm{N}-58^{\circ} 40^{\prime} 16,1^{\prime \prime} \mathrm{W}$, 01.IX.2008, S. Maciel \& M.R. Pietrobom 1030 (MG, PMA); Almeirim, $00^{\circ} 48^{\prime} 44,8^{\prime \prime} \mathrm{S}-53^{\circ} 56^{\prime} 55,7^{\prime}$ 'W, 26.X.2008, S. Maciel 1243 (MG, PMA); idem, $00^{\circ} 50^{\prime} 42,6^{\prime \prime} \mathrm{N}-53^{\circ} 56^{\prime} 58,2^{\prime \prime} \mathrm{W}, 30 . \mathrm{X} .2008$, S. Maciel \& M.G.C. Souza 1376 (MG, PMA).

6. Selaginella producta Baker, J. Bot. 21(8): 243. 1883.

Fig. $4 \mathrm{~d}-\mathrm{f}$

Caule não articulado, paleáceo a verde claro, não flageliforme, 2-pinado. Rizóforos distribuídos por toda a planta. Microfilos laterais ovado- lanceolados, ápice obtuso a agudo, base desigual com a porção acroscópica muito maior e sobrepondo o caule, sem aurículas, face superior glabra, margem acroscópica denticulada a ciliada. Microfilos dorsais ovados, ápice longamente agudo a acuminado, base sem aurículas, margens denticuladas. Microfilos axilares ovado-deltados, ápice obtuso, base truncada a sub-cordiforme, sem aurículas, com as margens denticuladas. Estróbilo quadrangular. Esporofilos monomorfos. Esporofilo dorsal verde escuro, ascendente; esporofilo ventral verde, levemente patente a ascendente.

A espécie distribui-se no Panamá, Trinidad e Tobago, Colômbia, Venezuela, Guiana, Suriname, Guiana Francesa, Peru (Smith 1995) e Brasil, onde é conhecida nos estados do Amazonas, Pará, Alagoas, Bahia, Goiás, Minas Gerais e Paraná (Costa \& Pietrobom 2010). Na área estudada $S$. producta assemelha-se à S. revoluta Baker, distinguindo-se por esta última possuir microfilos laterais frequentemente revolutos e com longos cílios, microfilos dorsais usualmente menores, mais estreitos e mais agudos, enquanto que $S$. producta possui os microfilos laterais planos e denticulados e os microfilos dorsais ovados. Além disso, S. producta geralmente possui idioblastos conspícuos nos microfilos dorsais. Coletada como terrícola ao longo da trilha e como rupícola às margens de um igarapé. Floresta Ombrófila aberta e floresta submontana aberta com predomínio de Cecropia Loefl., entre 300-570 m de altitude.

Material selecionado: BRASIL. PARÁ: Alenquer/ Monte Alegre, 00 $58^{\prime} 10,9^{\prime \prime}$ S-55 $55^{\circ} 3$ '0,77'W, 17.IV.2008, S. Maciel 444 (MG, PMA); Oriximiná, $01^{\circ} 16^{\prime} 00,3^{\prime \prime} \mathrm{N}-$ $58^{\circ} 41^{\prime} 45,5^{\prime}$ 'W, 29.VIII.2008, S. Maciel \& M.R. Pietrobom 932 (MG, PMA); idem, $01^{\circ} 16^{\prime} 52,8^{\prime \prime} \mathrm{N}-$ 58 41'03,3”'W, 07.IX.2008, S. Maciel \& M.R. Pietrobom 1119 (MG, PMA); idem, $1^{\circ} 16^{\prime} 16,8^{\prime \prime} \mathrm{N}-58^{\circ} 48^{\prime} 0,6^{\prime \prime} \mathrm{W}$, 04.IX.2008, M.R. Pietrobom \& S. Maciel 8037 (MG, PMA); Faro, margem esquerda do Rio Nhamundá, 142'19,8"S-57'11'47,7'W, 24.I.2008, M.R. Pietrobom \& G. Teixeira 7497 (MG, PMA).

7. Selaginella radiata (Aubl.) Spring, Bull. Acad. Roy. Sci. Bruxelles 10: 143, no 54. 1843.

Fig. 5a-c

Caule não articulado, paleáceo a verde claro, não flageliforme, 2-3-pinado. Rizóforos restritos à base do caule. Microfilos laterais ovadolanceolados, ápice agudo, base assimétrica com a porção acroscópica sobrepondo o caule, longos cílios hialinos presentes na base (mais abundantes na porção acroscópica). Microfilos dorsais 
ovados, ápice aristado, base sem aurícula, margem basal longamente ciliada. Microfilos axilares lanceolados, ápice agudo, base arredondada, sem aurículas e com longos cílios. Estróbilo quadrangular. Esporofilos monomorfos. Esporofilo dorsal verde, ascendente; esporofilo ventral verde claro, levemente patente a ascendente.

Distribui-se na Colômbia, Venezuela, Guiana, Suriname, Guiana Francesa, Equador (Vareschi 1968; Alston et al. 1981) e Brasil, onde possui registros nos estados do Pará, Maranhão e Mato Grosso. S. radiata pode ser facilmente distinguida das demais espécies ocorrentes na área pelo hábito ereto, pela presença de longos cílios hialinos na base dos microfilos (nos microfilos laterais são mais abundantes na porção acroscópica) e pelos microfilos dorsais com ápice aristado. Coletada como terrícola às margens da trilha e às margens de um igarapé. Floresta ombrófila aberta de terra firme, entre 190-600 m de altitude.
Material selecionado: BRASIL. PARÁ: Almeirim, 00'49'51,9"N-5357'19,6”'W, 27.X.2008, S. Maciel

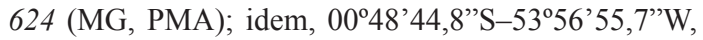
26.X.2008, S. Maciel 1245 (MG, PMA); idem, $00^{\circ} 51^{\prime} 09,5^{\prime}{ }^{\prime} \mathrm{N}-53^{\circ} 57^{\prime} 08^{\prime}$ 'W, 30.X.2008, S. Maciel \& M.G.C. Souza 1375 (MG, PMA); Alenquer, 11.VI.2008, J.M. Costa 636 (MG, PMA); Alenquer/Monte Alegre,

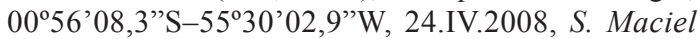
648 (MG, PMA).

8. Selaginella revoluta Baker, J. Bot. 21(5): 141, no 45.1883.

Fig. $5 \mathrm{~d}-\mathrm{f}$

Caule não articulado, paleáceo, não flageliforme, 1-2-pinado. Rizóforos distribuídos por toda a planta. Microfilos laterais oblongolanceolados, ápice obtuso, base assimétrica com a porção acroscópica ciliada e sobrepondo o caule, face superior glabra ou com curtos tricomas, principalmente próximo à margem, margem basioscópica geralmente revoluta. Microfilos dorsais ovados, ápice aristado, base levemente
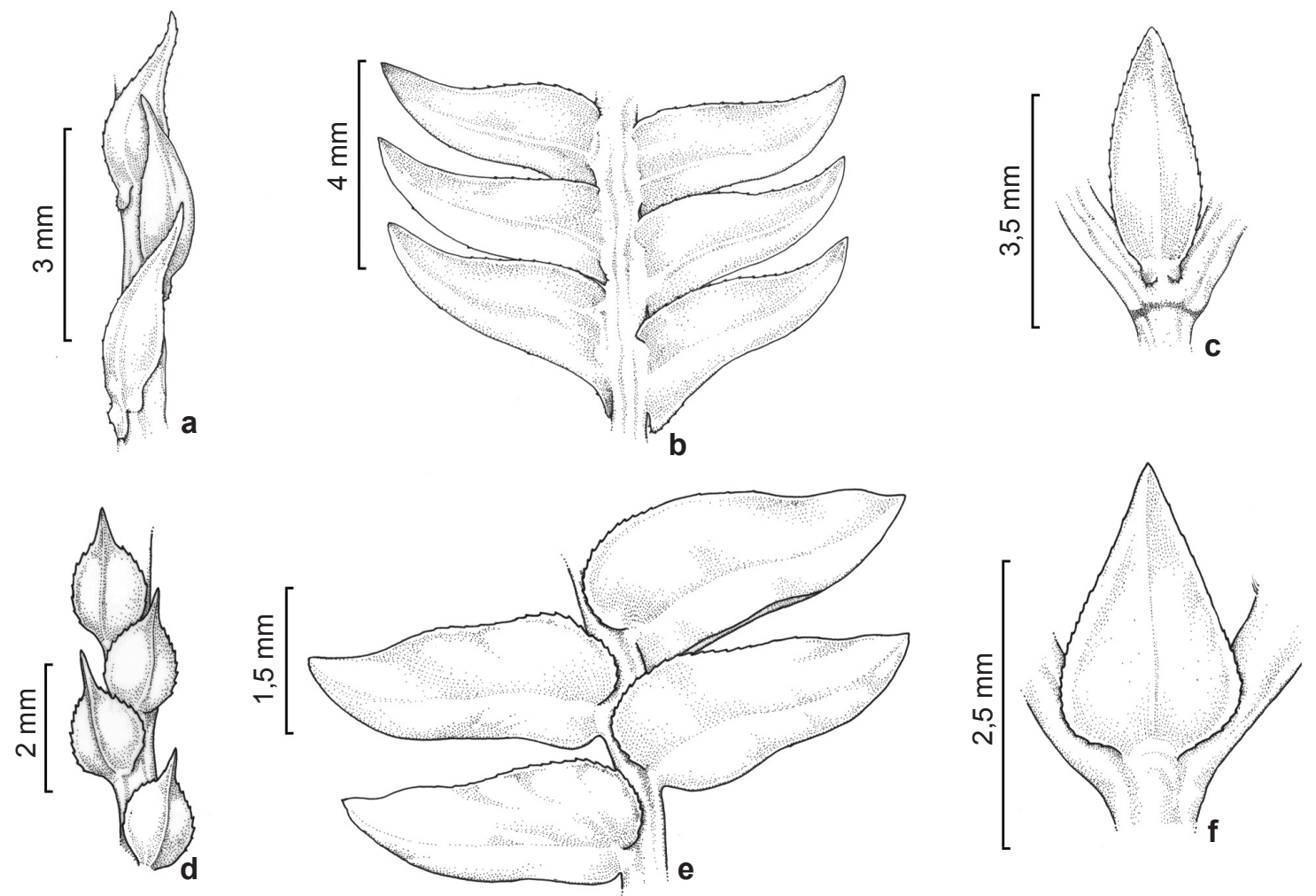

Figura 4 - a-c. Selaginella parkeri (S. Maciel \& M.G.C. Souza 1376). a. microfilos dorsais. b. microfilos laterais. c. microfilo axilar. d-f. Selaginella producta (S. Maciel \& M.R. Pietrobom 1119). d. microfilos dorsais. e. microfilos laterais. f. microfilo axilar.

Figure 4 -a-c. Selaginella parkeri (S. Maciel \& M.G.C. Souza 1376). a. median microphylls. b. lateral microphylls. c. axillary microphyll. d-f. Selaginella producta (S. Maciel \& M.R. Pietrobom 1119). d. median microphylls. e. lateral microphylls. f. axillary microphyll. 

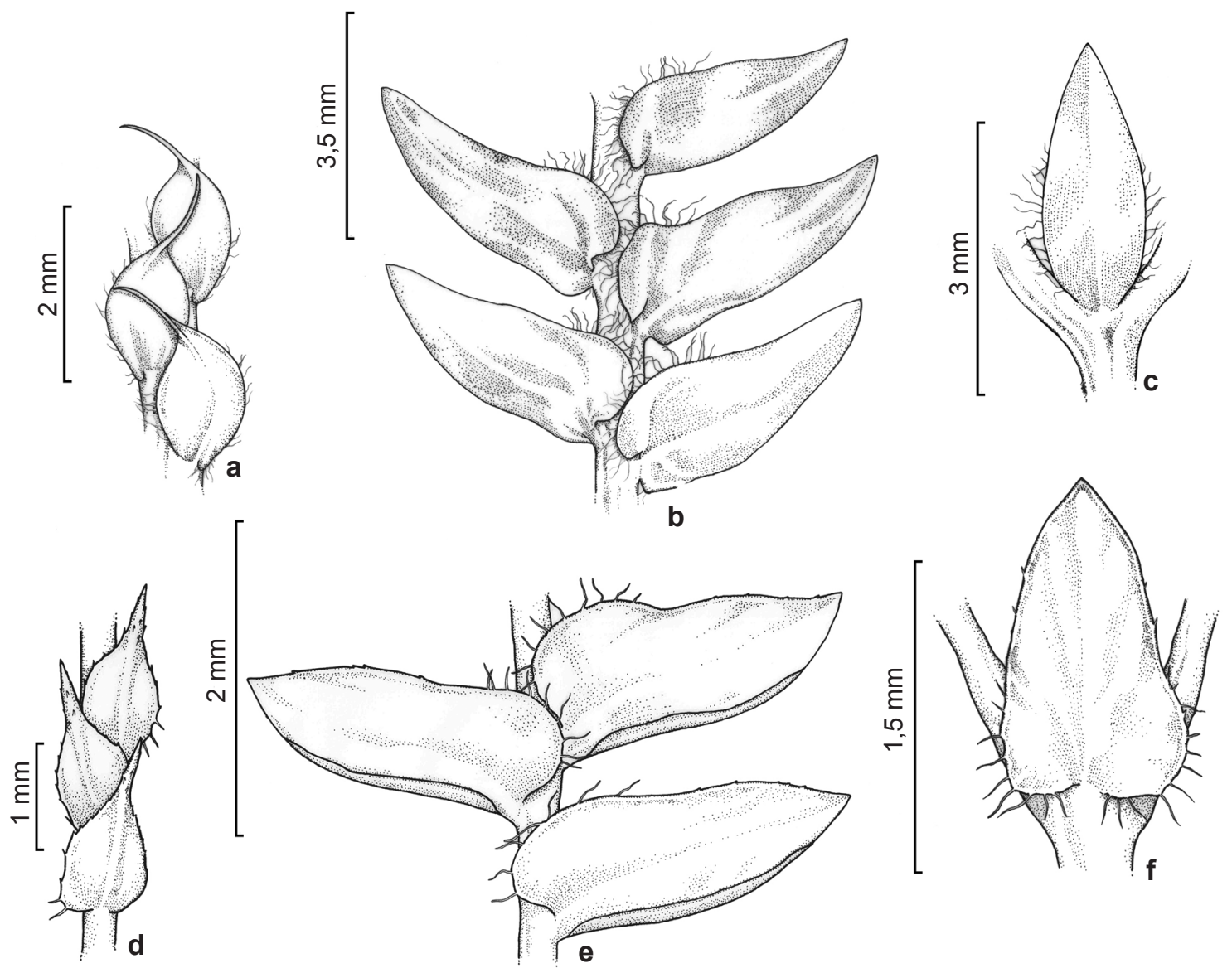

Figura 5 - a-c. Selaginella radiata (S. Maciel 1245). a. microfilos dorsais. b. microfilos laterais. c. microfilo axilar. d-f. Selaginella revoluta (S. Maciel 647). d. microfilos dorsais. e. microfilos laterais. f. microfilo axilar.

Figure 5 - a-c. Selaginella radiata (S. Maciel 1245). a. median microphylls. b. lateral microphylls. c. axillary microphyll. d-f. Selaginella revoluta (S. Maciel 647$)$. d. median microphylls. e. lateral microphylls. f. axillary microphyll.

assimétrica com a porção externa um pouco maior, porém sem formar aurícula, margem denticulada a curto-ciliada. Microfilos axilares oblongo-deltados, ápice obtuso a agudo, base sub-cordiforme com dois pequenos lobos ciliados, porém sem formar aurículas. Estróbilo quadrangular. Esporofilos monomorfos. Esporofilo dorsal verde escuro, ascendente; esporofilo ventral verde, levemente patente a ascendente.

A espécie distribui-se em Trinidad e Tobago, Colômbia, Venezuela, Guiana, Suriname, Guiana Francesa, Peru e Brasil, onde era conhecida apenas nos estados do Amazonas e Amapá (Smith 1995), sendo agora registrada no Pará. S. revoluta difere das demais espécies registradas na área pela base dos microfilos ciliada, margem basioscópica do microfilo lateral revoluta e microfilo dorsal com o ápice aristado. Esta espécie pode apresentar pubescência próximo à margem superior do microfilo lateral, porém, esta característica raramente foi observada. Coletada como epífita sobre raízes de cactácea. Floresta submontana densa com predomínio de grotas, igarapés e cipós, ca. $600 \mathrm{~m}$ de altitude.

Material examinado: BRASIL. PARÁ: Alenquer/Monte Alegre, Floresta Estadual do Trombetas, $00^{\circ} 56^{\prime} 08,3$ ' 'S5530'02,9”'W, 24.IV.2008, S. Maciel 647 (MG, PMA).

9. Selaginella sandwithii Alston, Bull. Brit. Mus. (Nat. Hist.), Bot. 9(4): 289. $1981 . \quad$ Fig. 6a-d

Caule não articulado, paleáceo a verde claro, não flageliforme, 2-3-pinado. Rizóforos presentes apenas nos $2 / 3$ basais. Microfilos laterais ovadodeltados, ápice agudo, base assimétrica com a porção 
acroscópica sobrepondo o caule, face superior com curtos tricomas principalmente próximo à margem, margem acroscópica denticulada a curtociliada. Microfilos dorsais ovados, ápice aristado, base sem aurículas, margens denteadas a curtociliadas com uma faixa conspícua de células mais claras. Microfilos axilares ovado-deltados, ápice acuminado, base curtamente cuneada, margens denticuladas a curto-ciliadas com uma faixa conspícua de células mais claras, sem aurículas. Estróbilo quadrangular. Esporofilos monomorfos. Esporofilo dorsal verde, ascendente; esporofilo ventral verde, levemente ascendente.

Distribui-se na Guiana, Suriname, Guiana Francesa (Alston et al. 1981; Funk et al. 2007), sendo este o primeiro registro no Brasil. $S$. sandwithii é caracterizada pelo hábito ascendente a ereto, caule sem ápice flageliforme (raramente com os ramos laterais flageliformes), microfilos laterais denticulados com curtos tricomas sobre a face superior, principalmente próximo às margens e micrósporos verrucosos. Dentre as espécies que ocorrem na Região Norte do Brasil, S. sandwithii pode ser confundida com $S$. flagellata, diferindo por esta última apresentar caule com ápice flageliforme e micrósporos com papilas alongadas (Alston et al. 1981), com S. muscosa Spring, diferindo principalmente por esta possuir hábito prostrado e com $S$. brevifolia Baker, diferindo por esta possuir microfilos laterais ciliados.

A presença de tricomas nos microfilos de Selaginella é incomum (Crabbe \& Jermy 1973). Contudo, Valdespino (1992) comenta que espécies sul-americanas como $S$. hirsuta Alston ex Crabbe \& Jermy, S. pubens A.R. Sm., S. smithiorum Valdespino, S. tyleri A.C. Sm. e S. terezoana Bautista possuem tricomas em uma ou ambas as superfícies dos microfilos. Posteriormente, esse caráter foi reportado para espécies da América Central como S. correae Valdespino (i.e. Valdespino 1993) e S. hirtifolia Valdespino (i.e. Mickel et al. 2004) e para outras espécies centro e sul-americanas pertencentes à Selaginella subg. Heterostachys (i.e. Valdespino 1995). Mais recentemente, este mesmo caráter foi observado em outras cinco espécies caribenhas (i.e. Caluff \& Shelton 2009).

$\mathrm{Na}$ descrição original de S. sandwithii (i.e. Alston et al. 1981), os autores informam a presença de papilas unicelulares na face superior dos microfilos laterais. De acordo com Metcalfe \& Chalk (1979) não existe uma clara distinção entre tricomas unicelulares e papilas. Payne (1978) define papila como uma projeção originada de uma única célula epidérmica e define tricoma como qualquer excrescência epidérmica que impeça classificar a superfície do vegetal como glabra. Desta forma, de acordo com o que se observa na micrografia apresentada pelos autores (i.e. Alston et al. 1981 p. 291 fig. 13d) bem como em nossas observações, achamos mais coerente tratar tal estrutura como tricoma. Coletada como terrícola ao longo da trilha e como rupícola às margens de um igarapé e em paredão rochoso no topo da serra. Floresta ombrófila aberta, entre 450-800 m de altitude.

Material examinado: BRASIL. PARÁ: Oriximiná, 01'16'28,8'N-58'39'41,9'W, 01.IX.2008, S. Maciel \& M.R. Pietrobom 1013 (MG, PMA); idem, $01^{\circ} 16$ '28, $8^{\prime \prime} \mathrm{N}-$ 58'39'41,9'W, 01.IX.2008, S. Maciel \& M.R. Pietrobom 1015 (MG, PMA); idem, 01¹6'52,8”N-5841'03,1”W, 07.IX.2008, M.R. Pietrobom \& S. Maciel 8081 (MG, PMA).

10. Selaginella sulcata (Desv. ex Poir.) Spring ex Mart., Flora 2: 126. $1837 . \quad$ Fig. 6e-g Caule articulado, paleáceo a verde claro, não flageliforme, 2-3-pinado. Rizóforos distribuídos por toda a planta. Microfilos laterais lanceolados, ápice agudo, base com duas aurículas curto-ciliadas aproximadamente iguais, face superior glabra. Microfilos dorsais ovados, ápice aristado, base com uma aurícula curto-ciliada, margens denticuladas. Microfilos axilares lanceolados, ápice obtuso a agudo, base com duas aurículas curto-ciliadas, margens denticuladas. Estróbilo quadrangular. Esporofilos monomorfos. Esporofilo dorsal verde, ascendente; esporofilo ventral verde, ascendente.

A espécie distribui-se no Suriname, Guiana Francesa, Bolívia, Paraguai e Argentina (Alston et al. 1981). No Brasil está amplamente distribuída, possuindo registros nos estados do Acre, Amazonas, Pará, Bahia, Ceará, Paraíba, Pernambuco, Mato Grosso e Mato Grosso do Sul e em todos os estados das Regiões Sudeste e Sul. S. sulcata distingue-se das demais espécies registradas na área pelo caule articulado, rizóforos distribuídos por toda a planta e pelas aurículas curtamente ciliadas nos microfilos axilares e laterais. Durante a observação do material notou-se que a presença/ ausência, bem como a abundância de tricomas nas margens dos microfilos provavelmente está relacionada à exposição à luz solar. As plantas de ambientes abertos e ensolarados geralmente possuem tricomas maiores e mais densos do que as que habitam ambientes sombreados, as quais, por vezes são glabras. Coletada como rupícola em 

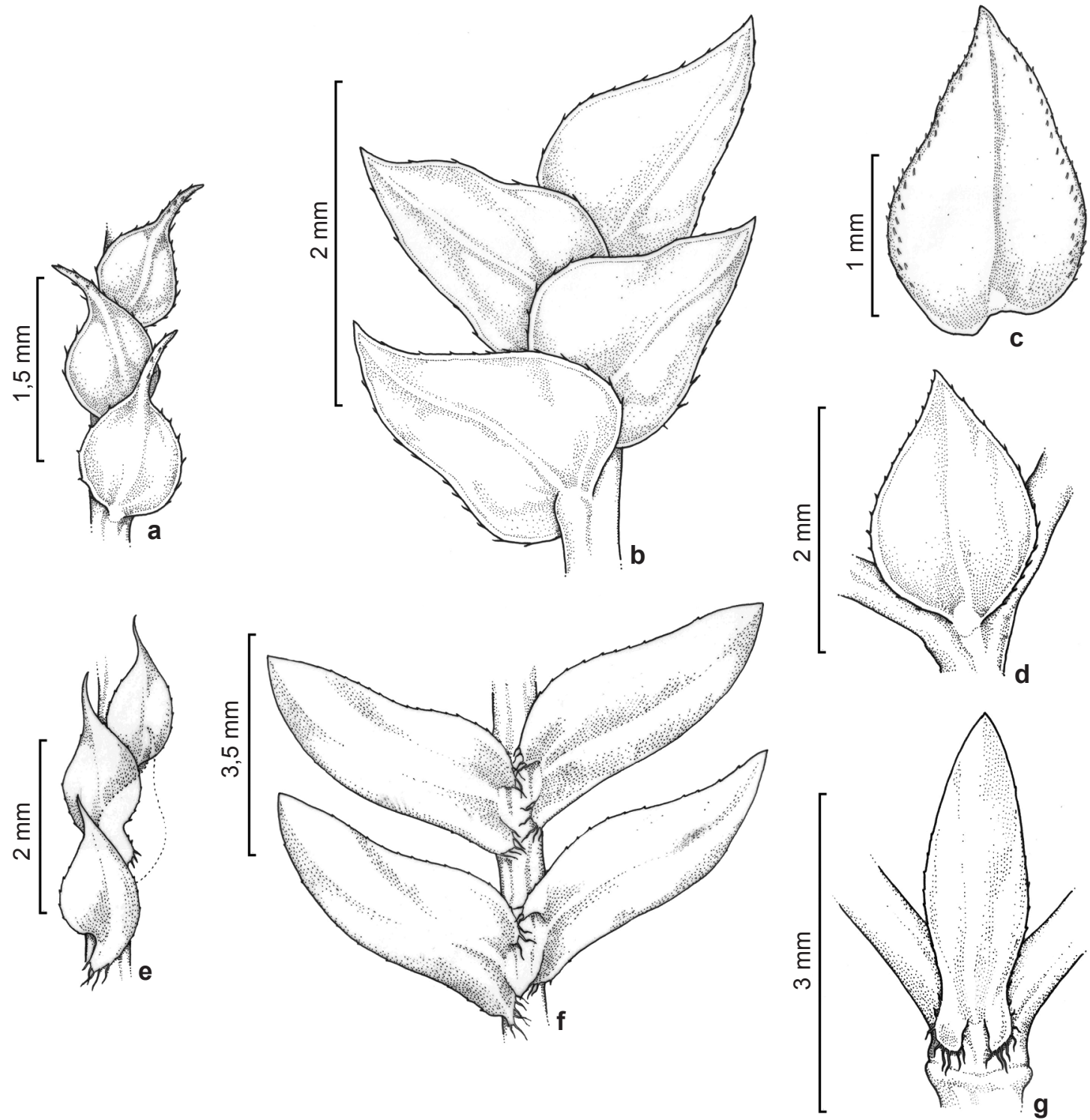

Figura 6 - a-d. Selaginella sandwithii (M.R. Pietrobom \& S. Maciel 8081). a. microfilos dorsais. b. face inferior dos microfilos laterais. c. face superior do microfilo lateral. d. microfilo axilar. e-g. Selaginella sulcata (S. Maciel 674). e. microfilos dorsais. f. microfilos laterais. g. microfilo axilar.

Figure 6 - a-d. Selaginella sandwithii (M.R. Pietrobom \& S. Maciel 8081). a. median microphylls. b. lower surface of lateral microphylls. c. upper surface of lateral microphylls. d. axillary microphyll. e-g. Selaginella sulcata (S. Maciel 674). e. median microphylls. f. lateral microphylls. g. axillary microphyll.

afloramento rochoso às margens da trilha e sobre rochas dentro de um igarapé. Floresta submontana densa com predomínio de grotas, igarapés e cipós, entre 500-600 $\mathrm{m}$ de altitude.

Material examinado: BRASIL. PARÁ: Alenquer/Monte Alegre, 22.IV.2008, S. Maciel 674 (MG, PMA); idem, 22.IV.2008, S. Maciel 682 (MG, PMA); Oriximiná, $01^{\circ} 15^{\prime} 51,5^{\prime} \mathrm{N}-58^{\circ} 40^{\prime} 47,7^{\prime} \mathrm{W}, 03 . \mathrm{IX} .2008$, S. Maciel \& M.R. Pietrobom 1094 (MG, PMA).

\section{Agradecimentos}

Ao CNPq, a bolsa de Mestrado concedida ao primeiro autor. À Conservação Internacional (Brasil) e Fundação Instituto para o Desenvolvimento da Amazônia, o financiamento do projeto e à Secretaria de Estado de Meio Ambiente do Pará, a concessão da licença para coleta. Ao Dr. Paulo Windisch, a confirmação de alguns espécimes 
de Lycopodiaceae. A João Silveira, a confecção das ilustrações. Aos revisores, as importantes contribuições dadas ao manuscrito.

\section{Referências}

Aleixo, A.; Poletto, F.; Lima, M.F.C.; Castro, M.; Portes, E. \& Miranda, L.S. 2011. Notes on the vertebrates of northern Pará, Brazil: a forgotten part of the Guianan Region, II. Avifauna. Boletim do Museu Paraense Emílio Goeldi - Ciências Naturais 6: 11-65.

Alston, A.H.G. 1936. The Brazilian species of Selaginella. Repertorium Specierum Novarum Regni Vegetabilis 40: 303-319.

Alston, A.H.G.; Jermy, A.C. \& Rankin, J.M. 1981. The genus Selaginella in tropical South America. Bulletin of the British Museum (Natural History) Botany 9: 233-330.

Assis, E.L.M. \& Labiak, P.H. 2009. Lycophyta da borda oeste do Pantanal, Mato Grosso do Sul, Brasil. Acta Botanica Brasilica 23: 703-712.

Avila-Pires, T.C.S.; Hoogmoed, M.S \& Rocha, W.A. 2010. Notes on the vertebrates of northern Pará, Brazil: a forgotten part of the Guianan Region, I. Herpetofauna. Boletim do Museu Paraense Emílio Goeldi - Ciências Naturais 5: 13-112.

Banks, J.A. 2009. Selaginella and 400 million years of separation. Annual Review of Plant Biology 60: 223-238.

Barros, I.C.L. \& Fonseca, E.R. 1996. Lycopodiaceae Myrbel de Brejo dos Cavalos - Caruaru, Estado de Pernambuco. Boletim da Sociedade Broteriana 2: 263-269.

Bautista, H.P. 1974a. Duas espécies novas de Selaginella da Amazônia. Boletim do Museu Paraense Emílio Goeldi 45: 1-5.

Bautista, H.P. 1974b. Uma Selaginella (Pteridophyta) do T.F. Roraima. Acta Amazonica 4: 19-21.

Caluff, M.G. \& Shelton, G. 2009. Review of hairy species of Selaginella (Selaginellaceae) of the West Indies, with description of two new species from Cuba. Willdenowia 39: 107-119.

Castellani, E.D. \& Freitas, C.A.A. 1992. Selagineláceas da Reserva Florestal Ducke (Manaus, AM). Acta Botanica Brasilica 6: 41-48.

Costa, J.M. \& Pietrobom, M.R. 2007. Pteridófitas (Lycophyta e Monilophyta) da Ilha de Mosqueiro, município de Belém, estado do Pará, Brasil. Boletim do Museu Paraense Emílio Goeldi - Ciências Naturais 2: 45-55.

Costa, J.M. \& Pietrobom, M.R. 2010. Samambaias e licófitas do Parque Ecológico do Gunma, município de Santa Bárbara do Pará, estado do Pará, Brasil. Rodriguésia 61: 223-232.

Crabbe, J.A. \& Jermy, A.C. 1973. Seven new species of Selaginella from tropical South America. American Fern Journal 63: 135-144.
Edwards, P.J. 1995. Selaginellaceae. In: Stannard, B.L. (ed.). Flora of the Pico das Almas, Chapada Diamantina, Bahia, Brazil. Royal Botanic Gardens, Kew. Pp. 83-84.

Edwards, P.J. 1998. The pteridophytes of the Ilha de Maracá. In: Milliken, W. \& Ratter, J.A. (eds.). Maracá: The Biodiversity and Enviroment of Amazonian Rainforest. Royal Botanic Garden, Edinburgh. Pp. 113-129.

Fée, A.L.A. 1869. Cryptogames vasculaires (fougères, lycopodiacées, hidropteridées, équisétacées) du Brésil I partie. Berger-Levrault \& Cia Libraires, Paris. 269p.

Fée, A.L.A. 1872-1873. Cryptogames vasculaires (fougères, lycopodiacées, hidroptéridées, équisétacées) du Brésil II partie. Berger-Levrault \& Cia Libraires, Paris. 115p.

Freitas, C.A.A. \& Windisch, P.G. 2005. Flora da Reserva Ducke, Amazonas, Brasil: Pteridophyta Lycopodiaceae. Rodriguésia 56: 67-68.

Fuchs-Eckert, H.P. 1986. Isoetáceas. In: Reitz, R. (ed.). Flora ilustrada catarinense. Herbário Barbosa Rodrigues, Itajaí. Pp. 1-42.

Funk, V.A.; Berry, P.E.; Alexander, S.; Hollowell, T.H. \& Kelloff, C.L. 2007. Checklist of the plants of the Guiana Shield (Venezuela: Amazonas, Bolivar, Delta Amacuro; Guyana, Surinam, French Guiana). Contributions of United States National Herbarium 55: $1-584$.

Góes-Neto, L.A.A. \& Pietrobom, M.R. 2012a. Aspleniaceae (Polypodiopsida) do Corredor de Biodiversidade do Norte do Pará, Brasil: um fragmento do Centro de Endemismo Guiana. Acta Botanica Brasilica 26: 456-463.

Góes-Neto, L.A.A. \& Pietrobom, M.R. 2012b. Novos registros de samambaias para a Amazônia Brasileira. Rodriguésia 63: 1151-1155.

Góes-Neto, L.A.A.; Pietrobom, M.R. \& Maciel, S. 2014. Schizaeales (Polypodiopsida) do corredor de biodiversidade do norte do Pará, Brasil. Pesquisas, Botânica 65: 245-256.

Hickey, R.J.; Macluf, C.C. \& Link-Pérez, M. 2009. Isoetes maxima, a new species from Brazil. American Fern Journal 99: 194-199.

Hickey, R.J.; Macluf, C.C. \& Taylor, W.C. 2003. A Reevaluation of Isoetes savatieri Franchet in Argentina and Chile. American Fern Journal 93: 126-136.

Hirai, R.Y. 2007. Selaginellaceae. In: Cavalcanti, T.B. (org.). Flora do Distrito Federal, Brasil. Embrapa Recursos Genéticos e Biotecnologia, Brasília. Pp. 161-168.

Hirai, R.Y. 2014. Selaginellaceae. In: Lista de Espécies da Flora do Brasil. Jardim Botânico do Rio de Janeiro. Disponível em <http://floradobrasil.jbrj. gov.br/jabot/floradobrasil/FB92047>. Acesso em 28 julho 2014. 
Hirai, R.Y. \& Prado, J. 2000. Selaginellaceae Willk. No Estado de São Paulo, Brasil. Revista Brasileira de Botânica 23: 313-339.

Huber, O. 2006. Herbaceous ecosystems on the Guayana Shield, a regional overview. Journal of Biogeography 33: 464-475.

Jermy, A.C. 1990. Selaginellaceae. In: Kramer, K.U. \& Green, P.S. (eds.). Pteridophytes and Gymnosperms Vol. I. In: Kubitzki, K. (ed.). The Families and Genera of Vascular Plants. Springer-Verlag, Berlin. Pp. 39-45.

Lellinger, D.B. 2002. A modern multilingual Glossary for taxonomic Pteridology. Spanish translation by C.H. Rolleri, French translation by C. Feuillet, Portuguese translation by P.G. Windisch. American Fern Society, Inc, Washington, DC. 263p.

Metcalfe, C.R. \& Chalk, L. 1979. Anatomy of the Dicotyledons. $2^{\text {nd }}$ ed. Vol.1. Claredon Press., Oxford. $148 \mathrm{p}$.

Mickel, J.T. \& Smith, A.R. 2004. The Pteridophytes of Mexico. Memoirs of the New York Botanical Gardens 88: 1-1054.

Mickel, J.T.; Smith, A.R. \& Valdespino, I.A. 2004. Selaginella. In: Mickel, J.T. \& Smith, A.R. (eds.). The Pteridophytes of Mexico. Memoirs of The New York Botanical Garden, New York. Pp. 550-602.

Mital, P.L. 1969. Epidermal studies in the genus Selaginella Beauv. Bulletin of the Botanical Survey in India 11: 150-160.

Nessel, H. 1927. As Lycopodiáceas do Brasil. Archivos de Botânica do Estado de São Paulo 1: 355-535.

Nessel, H. 1955. Lycopodiaceae. In: Hoehne, F.C. (ed.). Flora Brasilica 2. Instituto de Botânica, São Paulo. Pp. 1-131.

Øllgaard, B. 1992. Neotropical Lycopodiaceae - An Overview. Annals of the Missouri Botanical Garden 79: 687-717.

Øllgaard, B. 1995a. Lycopodiaceae. In: Berry, P. E.; Holst, B. K. \& Yatskievych, K. (eds.). Flora of the Venezuelan Guayana, 2. Pteridophytes, Spermatophytes: Acanthaceae-Araceae. Timber Press, Portland. Pp. 190-206.

Øllgaard, B. 1995b. Lycopodiaceae. In: Moran, R.C. \& Riba, R. (eds.). Flora Mesoamericana. Vol. 1. Psilotaceae a Salviniaceae. Universidad Nacional Autónoma de México, México. Pp. 05-21.

Øllgaard, B. 2012. Nomenclatural changes in Brazilian Lycopodiaceae. Rodriguésia 63: 479-482.

Øllgaard, B. \& Windisch, P.G. 1987. Sinopse das Licopodiáceas do Brasil. Bradea 5: 1-43.

Øllgaard, B. \& Windisch, P.G. 2014. Lycopodiaceae in Brazil. Conspectus of the family I. The genera Lycopodium, Austrolycopodium, Diphasium, and Diphasiastrum. Rodriguésia 65: 293-309.

Pará, 2008. Secretaria de Estado de Meio Ambiente. Unidade de Conservação estaduais do Pará na região da Calha Norte do Rio Amazonas. Belém.
Payne, W.W. 1978. A glossary of plant hair terminology. Brittonia 30: 239-255.

Pereira, J.B.; Windisch, P.G.; Lorscheitter, M.L. \& Labiak, P.H. 2012. Isoetes mourabaptistae, a new species from Southern Brazil. American Fern Journal 102: 174-180.

Pichi Sermolli, R.E.G. 1996. Authors of scientific names in Pteridophyta. Royal Botanic Gardens, Kew. 78p.

Pietrobom, M.R.; Maciel, S.; Costa, J.M.; Souza, M.G.C.; Trindade, M.J. \& Fonseca, M.S.S. 2009. Licófitas ocorrentes na Floresta Nacional de Caxiuanã, estado do Pará, Brasil: Lycopodiaceae e Selaginellaceae. Boletim do Museu Paraense Emílio Goeldi - Ciências Naturais 4: 37-45.

Prado, J. \& Freitas, C.A.A. 2005. Flora da Reserva Ducke, Amazonas, Brasil: Pteridophyta - Selaginellaceae. Rodriguésia 56: 98-102.

Prado, J. \& Hirai, R.Y. 2008. Criptógamos do Parque Estadual das Fontes do Ipiranga, São Paulo, SP. Pteridophyta: 13. Lycopodiaceae e 20. Selaginellaceae. Hoehnea 35: 543-552.

Ramos, C.G.V. \& Sylvestre, L. 2010. Lycopodiaceae no Parque Nacional do Itatiaia, RJ e MG, Brasil. Acta Botanica Brasilica 24: 25-46.

Rossetti, D. \& Toledo, P.M. 2007. Environmental changes in Amazonia as evidenced by geological and paleontological data. Revista Brasileira de Ornitologia 15: 251-264.

Silveira, A.A. 1898. Novae species Lycopodiacearum civitatis Minas Geraes (Brazil). Boletim/Comissão Geográfica e Geológica do estado de Minas Gerais 5: 117-145.

Smith, A.R. 1995. Selaginellaceae. In: Berry, P.E.; Holst, B.K. \& Yatskievych, K. (eds.). Flora of the Venezuelan Guyana 2. Pteridophytes, Spermatophytes: Acanthaceae-Araceae. Timber Press, Portland. Pp 296-314.

Spring, A.F. 1840. Lycopodineae. In: Martius, C.F.P. \& Eichler, A.G. (eds.). Flora Brasiliensis 1. Fleischer in Comm, Lipsiae. Pp 109-117.

Thiers, B. [continuously updated]. Index Herbariorum: A global directory of public herbaria and associated staff. New York Botanical Garden's Virtual Herbarium. Disponível em $<$ http://sweetgum.nybg. org/ih/> . Acesso em 03 maio 2013.

Tryon, R.M. \& Tryon, A.F. 1982. Ferns and allied plants, with special reference to Tropical America. SpringerVerlag, New York, Heidelberg, Berlin. 857p.

Valdespino, I.A. 1992. New species of Selaginella (Selaginellaceae) from the Guayana Highland of Venezuela. Brittonia 44: 199-207.

Valdespino, I.A. 1993. Notes on Neotropical Selaginella (Selaginellaceae), including new species from Panama. Brittonia 45: 315-327.

Valdespino, I.A. 1995. A monographic revision of Selaginella P. Beauv. subgenus Heterostachys Baker 
in Central and South America. Tese de Doutorado. The City University of New York, New York. 405p. Vareschi, V. 1968. Flora de Venezuela: Helechos. Vol. 1. Edición Especial. Instituto Botánico, Caracas. 1033p.

Windisch, P.G. 1991. Lycopsida austroamericana nova. Bradea 6: 21-24.
Windisch, P.G.; Ramos, C.G.V \& Øllgaard, B. 2014. Lycopodiaceae. In: Lista de Espécies da Flora do Brasil. Jardim Botânico do Rio de Janeiro. Disponível em < http://floradobrasil.jbrj.gov.br/ jabot/floradobrasil/FB91370 >. Acesso em 28 julho 2014. 